\title{
The Causes Which Influence the Change of Spatial Development Pattern in Taipei Metropolitan Area
}

\author{
K. C. Hsu, T. Y. Lai, and C. H. Lee
}

\begin{abstract}
Taipei metropolitan area has taken on a frog-leap and scattered landscape structure during the recent twenty years. Therefore, this study shall establish an evaluation system about the factors influencing the spatial development pattern in metropolitan area, through fuzzy deliph method to screen out possible 17 factors that influence the spatial development pattern of Taipei metropolitan area, and furthermore through multiple regression model to confirm 7 factors which have obvious significance. Among the 7 factors, some have positive impacts on the spatial sprawl trend, such as change rate of average housing price, growth rate of acreage in non-metropolitan land change cases deliberated by local government, distance from the development centre of the metropolitan area, quantity of railway stations, growth rate of the quantity of expressway or motorway interchanges, growth rate of the quantity of universities and colleges; but quantity of MRT stations has negative impact on the spatial sprawl trend.
\end{abstract}

Index Terms-Urban sprawl, landscape structure, fuzzy deliph method, Taipei metropolitan area.

\section{INTRODUCTION}

Urban change can be divided into one entity direction change like metropolitan spatial structural change or growth etc. and other directions' change concerning residents' social economic level, cultural literacy, educational status, consciousness of community and expectation to urban. Speaking of the metropolitan development experience of European and American countries since the twentieth century, along with the adjustment of population and economic industrial structure, growth of overall metropolitan space all takes on the pattern of outward expansion. Therefore, when discussing this topic, words like urban sprawl and suburbanization often arise to describe how frog-leap, inconsecutive and far from downtown land use pattern is generated in the process of metropolis moving from downtown to suburb due to land development and residents' living decision preference. For Taipei metropolitan area, it had taken on a frog-leap and scattered landscape structure [1] Through observing the development history of foreign metropolitan area, such trend of sprawl development will accompany numerous negative social economic impacts and environmental impacts. And as a consequence, government will also have to take endless and arduous land utilization

Manuscript received November 11, 2013; revised March 11, 2014.

Kuo-Cheng Hsu and Chin-Han Lee are with the Department of Urban Affairs and Environment Planning, Chinese Culture University, Taipei, Taiwan (e-mail: kcurban@gmail.com, james@waicheng.com.tw).

Tsung-Yu Lai is with the Department of Land Economics, National Chengchi University, Taipei, Taiwan (e-mail: tylai@nccu.edu.tw). policies and strategic schemes to reverse the metropolitan growing phenomenon which is against the sustainable development of environment.

Taking America as an example, since 1930, a series of New Deal adopted to cope with Great Depression made land use pattern appear Suburbanization; a lot of policies after the Second World War further accelerated the process of suburb land development and with the trend of industrial economy turning into service industry-oriented, residents' decision to housing zone bit produced more flexibility. No longer taking nearby workplace as the only factor into consideration [2], metropolitan area began to appear the situation of rapid sprawling development. As the result, consumption proportion of American overall land was far higher than the speed of population growth [3]. From 1940 to 1990, average land use area of each household enlarged gradually, but average population of each household reduced from 3.28 to 2.63 , which showed that the land area consumed by each person taking on an increasing trend [4]; in the aspect of influence of traffic, residents' traveling distance by vehicle averagely increased $4.2 \%$ each year from 1950 to 1990 , with average traveling speed slowing down sharply by about $50 \%$ and lengthening of running time relatively influenced residents' work and daily life, which showed that, according to the survey of Texas Transportation Association against 39 metropolitan areas all over America, financial loss caused by traffic jam reached up to 34 billion dollars each year [5]; besides, if situation of sprawling development kept being serious, there would be nearly 19 million hectares' land changing to development land all over America from 2000 to 2025 , except for damaging ecological balance of the environment, public facilities derived by which would also increase the government's financial deficit to 43.8 billion dollars. Therefore, seriousness of metropolitan sprawling development problem is apparent [6].

As to the reason for spatial pattern of Taipei metropolitan area gradually tending to sprawling development, that's the topic would be discussed in this study. So this study first will refer to related literatures to establish an evaluation system about the factors influencing the spatial development pattern in metropolitan area, through survey of fuzzy deliph questionnaire for experts to confirm possible factors considered by questioned experts that influence the spatial development pattern of Taipei metropolitan area, and furthermore through multiple regression model to see which factors actually causing spatial pattern change in Taipei metropolitan area from 1991 to 2006, which can serve as the reference for government to work out the metropolitan development policy. 


\section{DESIGN OF FUZZY DELIPH QUESTIONNAIRE}

Referring to relative studies, and taking specialty and background of the development of Taipei metropolitan area, this study lists 28 factors influencing the evolution of spatial development pattern of Taipei metropolitan area. According to the features, these factors can be classified into five levels like social economy, land use institution change, space location, traffic and public construction. Then, through questionnaire for experts, a system of factors influencing the evolution of spatial development pattern of Taipei metropolitan area is hoped to be established. As this study provides questioned experts with some possible factors influencing the spatial development pattern of Taipei metropolitan area to choose, subjective judgment to some degree is inevitable in the decision process. So comparing with using deliph method, applying fuzzy deliph method can appositely reflect different judgments of the questioned experts in professional consciousness. Therefore, when selecting the factors in this study, fuzzy deliph method is used to confirm the factors influencing the evolution of spatial development pattern of Taipei metropolitan area. In the process of conducting fuzzy deliph method, relative researchers often adjust some operation steps in different ways due to their consideration in limitation, particular emphasis, operating convenience of the studies, and this article refers to the operation concept and implementation steps suggested by [7], which is stated step by step as follows.

\section{A. First Step}

Design fuzzy deliph questionnaire and decide suited list of questioned experts. Then proceed with the procedure of questionnaire survey. Aiming at each evaluation item, interval value is given by questioned experts as what they believe, including three parts, among which, "minimum value" represents "the most conservative cognitive value" of quantized grade given by the expert for the evaluation item; then "maximum value" represents "the most optimistic cognitive value"; and "fittest value" represents "the most suitable cognitive value".

\section{B. Calculating the Minimum Value, Geometric Mean and Maximum Value}

Count up "the most conservative cognitive value" and "the most optimistic cognitive value" given by all the questioned experts for evaluation item. After getting rid of extreme value out of 2-times standard, further calculate the minimum value, geometric mean value and maximum value in "the most conservative cognitive value" and "the most optimistic cognitive value".

\section{Calculating the Triangle Fuzzy Number of "the Most}

Conservative Cognitive Value" and "the Most Optimistic Cognitive Value"

Respectively establish the triangle fuzzy number of "the most conservative cognitive value" and "the most optimistic cognitive value" aiming at evaluation item.

\section{Testing Experts' Opinions}

By following three ways, whether the experts' opinions for each evaluation item reaching a consensus can be tested, herein respectively stated as follows:
1) If the two kinds of triangle fuzzy number calculated in Step Three without duplication, it shows that the interval value of each expert's opinion has consensus sector and their opinions tend to be within the scope of this sector. At this moment, "the consensus important degree value" for evaluation item- $i$ can be shown as following formula.

$$
G^{i}=\frac{C_{M}^{i}+O_{M}^{i}}{2}
$$

2) If the two kinds of triangle fuzzy number calculated in Step Three with duplication, and the gray zone of fuzzy relation is less than the interval scope of "the optimistic cognitive geometric mean" and "the conservative cognitive geometric mean" given by questioned experts for the evaluation item, it shows that the interval value of each expert's opinion has no consensus sector, but the two questioned experts giving extreme opinions don't excessively enlarge the difference from other experts thereby resulting in dissension. At this moment, make "the consensus important degree value" for evaluation item- $i$ equal to the fuzzy set calculated after intersection of the fuzzy relation of two kinds of triangle fuzzy number, then continue to work out the quantized grade of the fuzzy set with maximum membership degree.

$$
\begin{gathered}
F^{i}\left(x_{j}\right)=\left\{\int_{x}\left\{\min \left[C^{i}\left(x_{j}\right), O^{i}\left(x_{j}\right)\right]\right\} d x\right\} \\
G^{i}=\left\{x_{j} \mid \max \mu_{F^{i}}\left(x_{j}\right)\right\}
\end{gathered}
$$

3) If the two kinds of triangle fuzzy number calculated in Step Three with duplication, and the gray zone of fuzzy relation is more than the interval scope of "the optimistic cognitive geometric mean" and "the conservative cognitive geometric mean" given by questioned experts for the evaluation item, it shows that the interval value of each expert's opinion has no consensus sector, and the two questioned experts giving extreme opinions excessively enlarge the difference from other experts thereby resulting in divergence. At this moment, need to collect the evaluation items, opinions of which are unable to reach convergence. Then proceed with the procedure of survey again aiming at the above evaluation items. During the process, may provide the experts with "the optimistic cognitive geometric mean" and "the conservative cognitive geometric mean" gained before as reference. If the evaluation items all reach convergence, then can proceed to calculate "the consensus important degree value".

\section{ANALYSIS OF THE FACTORS INFLUENCING THE SPATIAL DEVELOPMENT PATTERN OF TAIPEI METROPOLITAN AREA}

The fuzzy deliph questionnaire for experts in this study totally invited 17 experts to fill in. The specialty fields of those include national spatial planning, land use control, transportation planning. Recovery rate of the questionnaires 
is $100 \%$. After rough estimates, two extreme questionnaires are removed. Assessed value of all the elements in the rest 15 questionnaires reach convergence standard, which shows that questioned experts all reach a consensus at certain cognitive level for the influencing elements put forward in the questionnaire. Therefore, questionnaire for the second stage is unnecessary, and detailed statistic analysis can be directly conducted.

Through fuzzy deliph method, this study calculates each influencing element's geometric mean, verification value and the consensus important degree value. Among them, the higher the experts' consensus value is, meaning the higher the questioned experts' consensus level for the influencing elements is. Then this study takes arithmetic average 6.35 of all the 28 influencing factors' consensus value as the threshold. As is shown in Table I, after selecting there are totally 17 influencing elements taken into the evaluation system.

TABLE I: The Statistical TABLE OF THE RESUlts of FuZZY DELIPH QUESTIONNAIRE

\begin{tabular}{|c|c|c|c|c|c|c|c|}
\hline \multirow{2}{*}{$\begin{array}{l}\text { Item } \\
\text { factors* }\end{array}$} & \multicolumn{2}{|c|}{$\begin{array}{c}\text { fittest value } \\
\mathrm{Ai}\end{array}$} & \multicolumn{3}{|c|}{ geometric mean } & \multirow{2}{*}{$\mathrm{Zi}$} & \multirow[t]{2}{*}{$\mathrm{Gi}$} \\
\hline & $\min$ & $\max$ & $\mathrm{Ci}$ & $\mathrm{Ai}$ & Oi & & \\
\hline $\begin{array}{l}\text { Having MRT } \\
\text { station or not }\end{array}$ & 6 & 9 & 7.00 & 8.22 & 9.45 & 1.44 & 8.42 \\
\hline $\begin{array}{l}\text { Housing price } \\
\text { level }\end{array}$ & 5 & 9 & 5.87 & 7.18 & 8.76 & 0.89 & 7.72 \\
\hline $\begin{array}{l}\text { Developed } \\
\text { green area in } \\
\text { parks }\end{array}$ & 5 & 10 & 5.53 & 6.80 & 8.29 & 0.76 & 7.54 \\
\hline $\begin{array}{l}\text { Being close to } \\
\text { Taipei City or } \\
\text { not }\end{array}$ & 5 & 9 & 5.78 & 7.16 & 8.81 & 2.03 & 7.45 \\
\hline $\begin{array}{l}\text { Distance form } \\
\text { development } \\
\text { center of } \\
\text { metropolitan } \\
\text { area }\end{array}$ & 5 & 9 & 5.70 & 7.23 & 8.81 & 2.11 & 7.44 \\
\hline $\begin{array}{l}\text { Having } \\
\text { expressway } \\
\text { ramp and } \\
\text { motorway } \\
\text { interchange or } \\
\text { not }\end{array}$ & 5 & 9 & 5.88 & 7.37 & 8.61 & 1.72 & 7.43 \\
\hline Population & 5 & 9 & 5.51 & 6.96 & 8.74 & 2.24 & 7.41 \\
\hline $\begin{array}{l}\text { Important } \\
\text { public } \\
\text { construction } \\
\text { area }\end{array}$ & 5 & 9 & 5.48 & 6.82 & 8.65 & 2.17 & 7.40 \\
\hline $\begin{array}{l}\text { Having railway } \\
\text { station or not }\end{array}$ & 4 & 9 & 5.66 & 6.98 & 8.44 & 0.78 & 7.02 \\
\hline $\begin{array}{l}\text { Quantity of } \\
\text { universities and } \\
\text { colleges }\end{array}$ & 4 & 9 & 5.11 & 6.61 & 8.13 & 1.02 & 6.85 \\
\hline $\begin{array}{l}\text { Area of } \\
\text { enlarged } \\
\text { metropolis in } \\
\text { newly revised } \\
\text { planning cases } \\
\end{array}$ & 3 & 9 & 5.17 & 6.81 & 8.42 & 0.26 & 6.64 \\
\hline $\begin{array}{l}\text { Issued } \\
\text { implementing } \\
\text { metropolis } \\
\text { renewal case } \\
\text { area }\end{array}$ & 5 & 8 & 5.39 & 6.84 & 8.52 & 2.13 & 6.61 \\
\hline $\begin{array}{l}\text { Quantity of } \\
\text { basic } \\
\text { educational } \\
\text { facilities }\end{array}$ & 5 & 8 & 5.44 & 6.69 & 7.96 & 1.52 & 6.56 \\
\hline $\begin{array}{l}\text { Companies' } \\
\text { operational }\end{array}$ & 4 & 9 & 5.45 & 6.60 & 7.91 & 1.46 & 6.55 \\
\hline
\end{tabular}

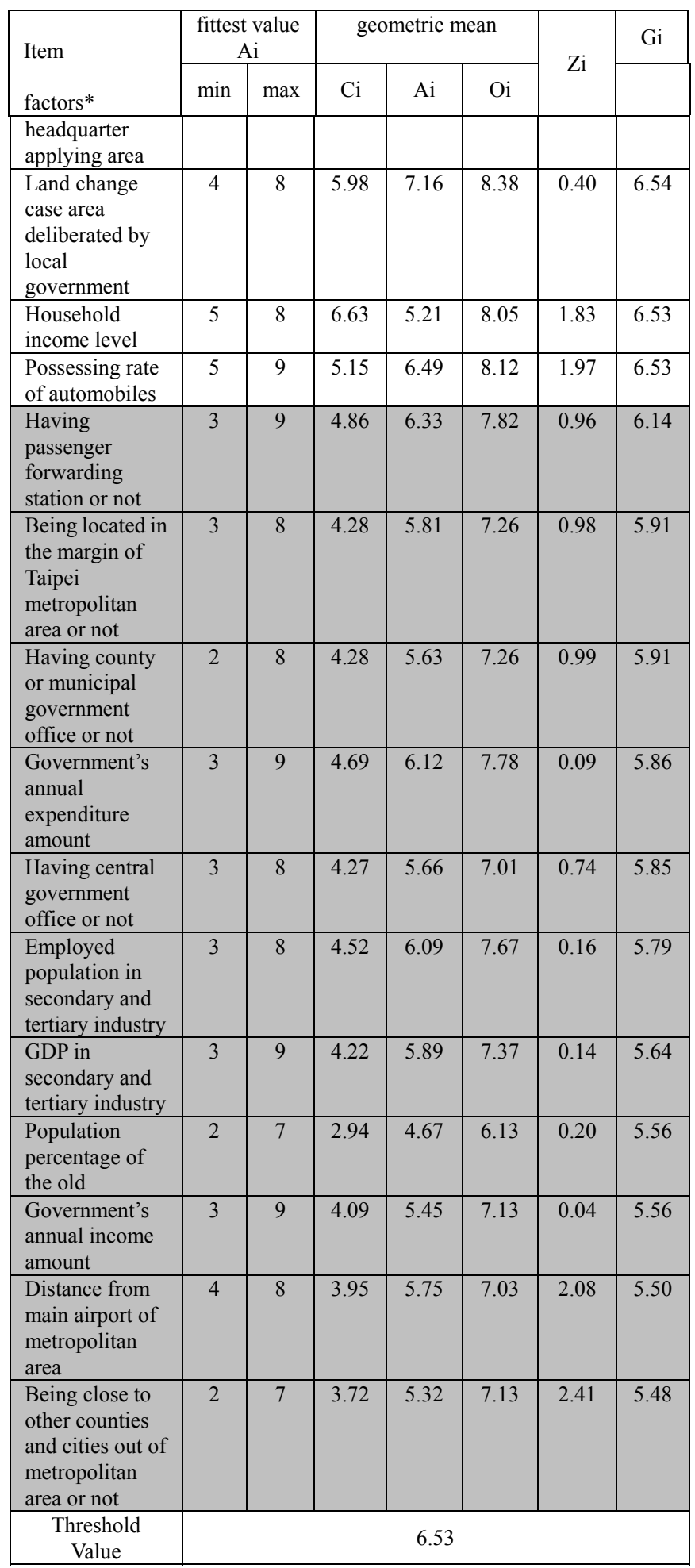

*: rank of influencing elements are ordered according to consensus important degree value Gi from low to high; shading means the influencing factors fail to pass the selecting threshold.

\section{DISCUSSION OVER THE REASONS WHICH INFLUENCE THE CHANGE OF SPATIAL DEVElopMENT PATTERN OF TAIPEI METROPOLITAN AREA}

This section is mainly through multiple regression model to confirm which factors actually cause the change of spatial development pattern of Taipei metropolitan area from 1991 to 2006. Then, thereby understand the impact of these factors toward spatial pattern. In the aspect of modeling, dependent variables adopt change rate of each administrative region's 
sprawl indices calculated by [8] within the scope of Taipei metropolitan area from 1991 to 2006. Independent variables mean the 17 factors influencing the spatial development pattern of Taipei metropolitan area selected from the results of fuzzy deliph questionnaire. However, "household income level" and "possessing rate of automobiles" are hard to be taken into modeling since the measure of statistical data is different from the real evidence scope adopted in this study. So there are totally 15 independent variables taken into modeling at last.

TABLE II: RESULT OF MULTIPLE REGRESSION MODEL CALIBRATION OF THE FACTORS INFLUENCING THE SPATIAL DEVELOPMENT PATTERN

\begin{tabular}{|c|c|c|c|c|}
\hline Variable ${ }^{\text {Item }}$ & $\begin{array}{l}\text { coefficient } \\
\text { value }\end{array}$ & $\begin{array}{c}\text { standard } \\
\text { deviation }\end{array}$ & t value & VIF \\
\hline Constant (intercept) & -0.173 & 0.353 & -0.489 & - \\
\hline $\begin{array}{l}\text { Change rate of average } \\
\text { housing price }\end{array}$ & $1.917^{* * *}$ & 0.595 & 3.223 & 1.897 \\
\hline $\begin{array}{l}\text { Growth rate of acreage in } \\
\text { non-metropolitan land } \\
\text { change cases deliberated by } \\
\text { local government }\end{array}$ & $0.516^{*}$ & 0.268 & 1.926 & 1.441 \\
\hline $\begin{array}{l}\text { Growth rate of issued } \\
\text { implementing metropolis } \\
\text { renewal case area }\end{array}$ & -0.249 & 0.112 & -1.358 & 2.229 \\
\hline $\begin{array}{l}\text { Distance from development } \\
\text { centre of metropolitan area }\end{array}$ & $2.059 \mathrm{E}-05$ & 0.000 & 2.201 & 1.926 \\
\hline $\begin{array}{l}\text { Being close to Taipei City } \\
\text { or not }\end{array}$ & 0.286 & 0.199 & 1.440 & 1.305 \\
\hline Quantity of MRT stations & $-0.189^{* * *}$ & 0.061 & -3.075 & 3.522 \\
\hline Quantity of railway stations & $0.216^{* *}$ & 0.089 & 2.426 & 1.484 \\
\hline $\begin{array}{l}\text { Growth rate of the quantity } \\
\text { of expressway ramp or } \\
\text { motorway interchanges }\end{array}$ & $0.328^{* * *}$ & 0.087 & 2.426 & 1.578 \\
\hline $\begin{array}{l}\text { Growth rate of important } \\
\text { public construction } \\
\text { planning area }\end{array}$ & 0.052 & 0.049 & 1.042 & 1.353 \\
\hline $\begin{array}{l}\text { Growth rate of developed } \\
\text { green area in parks }\end{array}$ & -0.192 & 0.110 & -1.254 & 1.504 \\
\hline $\begin{array}{l}\text { Growth rate of the quantity } \\
\text { of universities and colleges }\end{array}$ & $0.787^{* * *}$ & 0.225 & 3.502 & 1.288 \\
\hline \multicolumn{5}{|c|}{$\mathrm{F}: 3.908^{* *}$} \\
\hline
\end{tabular}

Before model calibration, this study first knows the relevance between dependent variables and independent variables and the multicollinear situation among the independent variables through Correlation Analysis. During model calibration, based on selection of independent variables, it turns out that six dependent variables and independent variables have obvious relevance. Among those, three independent variables like "change rate of average housing price", "distance from development centre of metropolitan area" and "growth rate of the quantity of expressway ramp or motorway interchanges" pass the significant level of $\alpha=0.01$; some independent variables like "quantity of MRT stations" and "growth rate of the quantity of universities and colleges" pass the significant level of $\alpha=0.05$. Other variables fail to pass significant level calibration, which shows the relevance between dependent variables and these elements is not so obvious.
Moreover, when conducting independence calibration among independent variables, it turns out that "growth rate of companies' operational headquarter applying area" and "distance from development centre of metropolitan area" can't pass independence calibration as they have dependency; "growth rate of issued implementing metropolis renewal case area" has dependency with "having MRT station or not" and "distance from development centre of metropolitan area". Then in the stage of model calibration, these elements can be taken into consideration when selecting independent variables is required.

As is shown in Table II, The result presented by multiple regression model shows that 7 factors have significant impact in influencing the change of spatial development pattern of Taipei metropolitan area, with $\mathrm{Adj}-\mathrm{R}^{2}$ being 0.317 . To achieve the better result of model adaption, further conduct the deleting and combining test aiming at the elements without influence and through repeated screening process, the correct result of multiple regression calibration model is worked out (see details from Chart 2). Its explanatory power reaches 0.457 , and variance analysis of $F$ calibration also has significant level. Besides, VIF of each independent variable is all less than 10, so it's obvious that multicollinear does not exist among variables.

Further interpret the chart aiming at these significant influencing factors, which can be respectively stated as follows.

1) Coefficient of the factor "change rate of average housing price" is positive, which represents that rise of the housing price level in Taipei metropolitan area appearing a positive relation with sprawl development of the spatial pattern. To discuss the reasons, after observing the change of housing price level in each administrative region during 15 years, one can find that regions with relatively obvious housing price rising degree are mostly located in core zone of the metropolitan area, which accords with ordinary cognition of high housing price in Taipei downtown. In another word, with the situation of housing price constantly rising in core zone of Taipei metropolitan area, residents' house-purchasing behavior has to move to outskirts. This not only promotes land development activities in these regions to appear flourishing on the basis of certain demands, but also leads to the expanding development of spatial structure all over the metropolitan area.

2) Continuing to discuss based on the result, because the high housing price in downtown of Taipei metropolitan area makes people flinch, they have to seek their living space in outskirts and passively accept a lot of inconvenience brought about by living far from development center. Comparing with the expanding course of spatial structure in American metropolitan area, relative studies all pointed out that in the process of metropolis change in sprawl development pattern, vast of middle class chose to move to outskirts to pursue 
better living space and living quality, which results in high-quality and high-price single-family house becoming the main trend in outskirts. This not only caused environment pollution and security problems in downtown, but also led to housing price gradually turning low in downtown [9], [10], [11]. This is the significant difference between Taiwan and America in suburbanization.

3) Influencing factor of "growth rate of acreage in non-urban land change cases deliberated by local government" has positive impact to sprawl development of the spatial pattern. Since 2001, government changed the institution of non-urban land use and conferred deliberation rights and liabilities of non-urban land change cases less than 10 hectares to local government. The larger the applying area of such land change cases in a region is, the more scattered sprawling landscape of the spatial pattern in this region is.

4) In the aspect of space location, totally two influencing factors like "distance from development centre of metropolitan area" and "being close to Taipei City or not" are taken into multiple regression model. Among them, "distance from development centre of metropolitan area" has an obvious positive relation with dependent variable. That is, the further away from the development centre of Taipei metropolitan area, the more scattered patter appears in spatial development.

5) "Quantity of MRT stations", "quantity of railway stations" and "growth rate of the quantity of expressway ramp or motorway interchanges" represent three influencing elements in the aspect of traffic, which all have significant impact in change rate of sprawl indices. Among them, coefficient of "quantity of MRT stations" is minus, which shows that the more MRT stations are set in the scope of an administrative region, the tighter development tendency of the region will be. This phenomenon may be because that setting of MRT stations can promote the actual convenience in people's life. Then taking development risk and market acceptance into consideration, developers have high intention toward the region around the MRT stations. Therefore, in the administrative region with or planned to set MRT stations, development behaviors bunching around the stations are naturally generated. So tight development tendency appears on overall landscape structure.

6) Coefficient of "quantity of railway stations" and "growth rate of the quantity of expressway ramp or motorway interchanges" is positive, which represents that the more railway stations are or the higher the growth rate of the quantity of expressway ramp or motorway interchanges is, the more sprawling the development tendency of the spatial pattern is. The impact of such road transportation construction to spatial structure in metropolitan area is similar with the development features in European and American countries. Observing from America's experience, massive policies of constructing interstate highways resulted in promoting feasibility in outskirts, which was regarded as the critical element in sprawl development tendency of the spatial pattern in American metropolitan area by relative researchers [12], [13], [14]; the study of European Environment Agency also pointed out that, apart from residents' pursuing living environment and quality, among the reasons which caused sprawl development tendency in European regions, rapid expansion of transportation network was also a key factor [15].

7) In the aspect of public construction, "growth rate of the quantity of universities and colleges" appears a positive relation with sprawl development of the spatial pattern. To speculate its reason, if universities and colleges are newly set in an administrative region, commercial activities and students' living demands certainly will be driven in this region. Developers will also have intention to enter the market for the basis of certain demands and then activating real estate development behaviors in this region, which will lead to spatial sprawl development pattern.

\section{CONCLUSION}

This article according to relative literatures summarizes 28 influencing factors to spatial development pattern in five aspects like social economy, change of land use system, space location, traffic and public construction. Through fuzzy deliph method, there are totally 17 influencing factors passing the threshold value, which can be regarded as the factors influencing the spatial development pattern of Taipei metropolitan area based on questioned experts' specialty and study experience.

Further through multiple regression model, finally confirm the 7 factors which have significant impact in sprawl development tendency in Taipei metropolitan area. Among them, "change rate of average housing price" has positive impact in sprawl development pattern. After further analysis, regions with relatively obvious housing price rising degree are mostly located in core zone of the metropolitan area. Due to model setting at this stage, it can only be initially speculated that high-housing price phenomenon in downtown region may result in the tendency of residents' decision of housing purchasing deflect to outskirts region. So do developers' decision, because of relatively low land development difficulty and relatively high profit. So urban landscape produced frog-leap and scattered situation. Another influencing factor deserve to discuss is "growth rate of acreage in non-metropolitan land change cases deliberated by local government", which also appears a positive relation with sprawl development tendency, that is, such land change applying cases will cause scattered spatial development. However, the rights of deliberation which should have belonged to central responsible institutions are deputed to local government. This is an institutional changing behavior mainly to improve the deliberation operation efficiency. But on the contrary, it goes against with spatial compact development advocated by the government, which is also the further prudent consideration point for government's subsequent policy adjustment. Besides, in the aspect of traffic, "quantity of railway stations" and "growth rate of the 
quantity of expressway ramp or motorway interchanges" have positive impact in sprawl development tendency, which is similar with the empirical studies in European and American countries; "quantity of MRT stations" contributes to tight development of landscape pattern in a region. Seeing from planning concept of TOD, such phenomenon fits the expectation of government's policy implementation.

\section{REFERENCES}

[1] K. C. Hsu, T. Y. Lai, and S. L. Chan, "Spatial sprawl and compact development patterns and trends in the Taipei metropolitan area," City and Planning, vol. 37, no. 3, pp. 281-303, 2010.

[2] A. Nelson, "Characterizing exurbia," Journal of Planning Literature, vol. 6 , no. 4, pp. 350-368, 1992.

[3] S. Gardner, "The impact of sprawl on the environment and human health," in Urban Sprawl: A Comprehensive Reference Guide, D. C. Soule, Ed. Greenwood Press, 2006, pp. 240-259.

[4] H. L. Diamond, and P. F. Noonon, Land Use in America, Washington, D.C.: Island Press, 1996, p. 85.

[5] F. K. Benfield, D. R. Matthew, and D. D. T. Chen, Once There Were Greenfields: How Urban Sprawl is Undermining America's Environment, Economy and Social Fabric, Washington, D.C.: Natural Resources Defense Council, 1999, p. 35.

[6] R. W. Burchell, A. Downs, B. McCann, and S. Mukherji, Sprawl Cost - Economic Impacts of Unchecked Development, Washington D.C.: Island Press, 2005, pp. 38-79.

[7] T. B. Jeng, "Fuzzy assessment model for maturity of software organization in improving its staff's capability," M.S. thesis, Dept. Information Management. National Taiwan University of Science and Technology, Taiwan, 2001.

[8] K. C. Hsu, "A Study on the trend and causes of spatial development pattern change in the Taipei metropolitan area," Ph.D. dissertation, Dept. Land Economics. National ChengChi University, Taiwan, 2010.

[9] R. H. Ewing, "Characteristics, Causes, and Effects of sprawl: A Literature Review," Environmental and Urban Issues, vol. 21, no. 2, pp 1-15, 1994.

[10] D. Young, Alternatives to Sprawl, Cambridge, MA: Lincoln Institute of Land Policy, 1995.

[11] T. Schiller, "Sprawl: what is in a name," Business Review, Fourth Quarter, pp. 26-38.
[12] P. Mieszkowski and E. S. Mills, "The causes of metropolitan suburbanization," The Journal of Economic Perspectives, vol. 7, no. 3, pp. 135-147, 1993.

[13] D. C. Soule, "Historical framework: Cities and Their Regions, Suburbanization, and Federal Policies," in Urban Sprawl; $A$ Comprehensive Reference Guide, D. C. Soule, Ed. Greenwood Press, 2006, pp. 12-25.

[14] S. Weiler, "Pioneers of rural sprawl in the rocky mountain west," The Review of Regional Studies, vol. 33, no. 3, pp. 264-283, 2003.

[15] European Environment Agency, Urban Sprawl in Europe -The Ignored Challenge, Denmark: European Environment Agency, 2006, pp. 5-9.

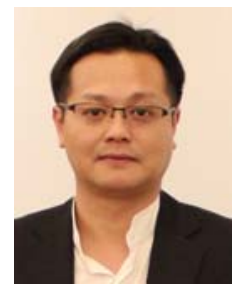

Kuo-Cheng Hsu is an assistant professor at Department of Urban Affairs and Environment Planning, Chinese Culture University, Taipei, Taiwan. $\mathrm{He}$ got $\mathrm{Ph} . \mathrm{D}$. in land economics from National Chengchi University in 2010. His recent research focuses on the change of metropolitan spatial structure, urban growth management, and the analysis of real estate market.

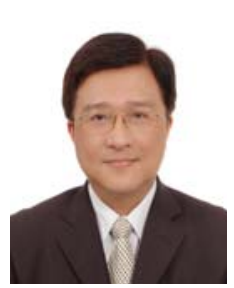

Tsung-Yu Lai is a professor at Department of Land Economics, National Chengchi University, Taipei, Taiwan. He got Ph.D. in urban and regional planning from University of Pennsylvania, America. His recent research focuses on the urban growth management, the institution of tax increment finance, and land use planning.

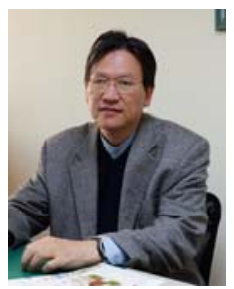

Chin-Han Lee is an associate professor at Department of Urban Affairs and Environment Planning, Chinese Culture University, Taipei, Taiwan. He got Ph.D. in land economics from National Chengchi University. His recent research focuses on the urban regeneration, real estate development, and urban and regional planning. 